\title{
The Minimal Structure of the Meaningful Movements in Albanian Language during the Poetical Speech (In the Poetical Speech of D.Mehmet)
}

\author{
Fitor Ollomani \\ University of Tirana \\ The Faculty of History and Philology \\ The Department of Linguistic \\ fitorollomani@yahoo.com
}

\section{Doi:10.5901/mjss.2014.v5n13p0545}

\section{Abstract}

In our treatment we are going to observe and interpret in different points of view the minimal structures of the meaningful movements in Albanian language, in the poetical speech of Din Mehmet. The theoretical view over the minimal structures of the first meaningful movements. The observation and the interpretation of the full semantic demonstration of a word, regarding the different linguistic directions. The interprentation of trinity (as a conventional sign, in relations with other words and with the user) of the fullness of a word during the (poetical) speech and the implements needed to realise it. The observation and the interpretation of the minimal structures of the meaningful movements in the poetical speech of Din Mehmeti, in both superficial and deep structures. The interpretation of the meaningful movements in the meaningful hierarchy of different lexemas at the minimal structure of the speech flow (poetical) without excluding the larger structures in the level of a sentence as a possibility not only in the Albanian language.

Keywords: Minimal structure, deep structure, superficial, arbitrary sintagma, prime nomination, poetical semantic.

The whole word as a linguistic sign consists of three parts. The existence as a conventional sign, in relation with the others and in relation with the user. Researchers have questined three aspects which originate from Ch. Morris. These three aspects of the word are both conservative and flexible for what they sign in relation with the other signs and with the user too. The better perception of the word is realised regarding the above trinity where each aspect is important for what it offers. The word comes in a formal and meaningful way actualizing different meanings from the hierarchy or it creates different meanings during its presence in the linguistic linear flow.

Excactly during its presence in speach we find the polisemic genesis of the word. Connecting the words,in their linear order,the nature of this connection is defined by many factors. The first conditioning is of the semantic nature ${ }^{1}$ (Giorgo Graffi,(1994)2003;244) although the lexical element of a certain voice(verbal) is presented individually from its eptic element (Giorgio Graffi,(1994)2003;244).The relationship between the eptic and semantic is necessary for the superficial structures of speech,but in deep structures this relationship is not essentially necessary.However in deep structures the semantic relation among words is needed more.

John Lynos also treats this relationship when he uses the terms eptic and semantic acceptance and unacceptance. The formal acceptance is present according to the normative rules of the the traditional grammar but this acceptance can be semantic unacceptance which at least can be explained as "meaningless" words (John Lynos,(1968)2001;390). The meaningful words have nothing to do with the serving words but from its meaningless springs their relationship in the structures of the speech of this kind:Green yellow ${ }^{2}$ the love of hate,the sheep ate the wolf,I bit with my fallen teeth.

In the grammatical aspect (eptic) the above structures are meaningful,but in the semantic aspect they are not so, they are changed into "meaningless". Their meaningless is unacceptable semantically in the speaker's consciousness although it is acceptable according to the formal rules of building the structure of the unit.In different linguistic studies it has been declared that the semantic relationship defines the connection among words, it creates the syntactic unit structures and the whole meaningful transmission of a text but it does not create rules for the syntactic units which remain

${ }^{1}$ This conditioning is possible only in the semantic relationship of the speaker's consciousness,but not a conditioning in the nature of connections as part of the grammatical structure

2 However, in this structure we can see the psico-linguistic element in understanding the notion of colours in different languages 
completely independent from the semantic conditionings.

How much does this formal relationship affect the linear flow of the words with each other? Certainly in the linear way of of ordering the words a main factor is their form.

The formal importance of connecting the words has made it possible that during the years the linguistic study the linguistic forms of these relations in a detailed way. These have created linguistic orientations deply formal which were not considered very important the relationship form-meaning as a vital symbiosis.

The relationship between the form and the meaning ${ }^{3}$ is essential in what the generativists consider a candidate grammar of the relevant language.

Equally important is the the relationship in fulfilling the"the entire linguistic meaning of a phrase which consists of the lexical meaning of the special ${ }^{4}$ words and that of the structural meanings..... which constitute the grammar of a language" (John Lynos,(1968)2001;403).

The entire realization of the meaning is possible only when the speech of a language is shown, in which according to "Fries" the structural meaning is full in the three aspects: the meaning of the grammatical elements, the meaning of the grammatical functions, "the meaning " was said., but the meaning of the smallest syntactic units is sum of the lexical and grammatical meaning.

Also, this makes the hypothesis go forward that the process of "understanding a sentence" can be partly explained according to the notion of of the linguistic level. Especially, to understand a sentence it is important to know the basic sententes from where they originate (more exactly the last lines that are in the base of these sentences) and the structure of the syntagma of each of the first componentsas well as the history of tansforming the given sentences into the basic ones (Noma Nhomsky,(1957)2011;113). The structure of syntagma signs the starting point of fulfilling the functions of the words in the lexical and grammatical aaspect. In the traditional linguistic such structures are named word groups,in modern linguistic they are named syntagma. The semantic relations of the words in the group of syntagmas are formed being based on the naturallity of connections known from the linguistic consciousness(the independent grammar from the lexical meaning), always meaningful and formal (Noma Chomsky,(1957)2011;113).

In the hierarchic structures of elements of syntagma one element serves as a leader,which is called the head and the other serves as a subordinate element but both compliment each other in every aspect. Depending on the type of speech that the head is, we have the classifications of syntagma: noun syntagma NS(the warm sun),verbal syntagma VS (I heard the news this afternoon),the adjectival syntagma Adj.S (attentive at work), adverbial syntagma Adv.S (tomorrow before noon),preposition syntagma PS(in front of the house) $)^{5}$

The nature of the components of syntagma is defined by the the lexico-grammatical nature of of the head of syntagma.This is the reason we have some kinds of connections:connections with adoption(good people),with direction(golden ring)and with compound(speak furiously).On the other hand the relation among the components of syntagma are of some kinds:predicative relation(the house is changed into ruins)objective(I see the lonliness),determinant (golden hand), complemental (he goes upstairs). (Rami Memushaj,2003;264)

In these structures the first meaningful movement should be searched in the hierarchic semantic structures thanks to the lexico-grammatical presenece of language.In these structures we should search the third principle of the semantic presentation:"In what ways are the meanings of a word included in the meaningful structure of another?"(M.Gareth Gaskell 2007;197)

In order to see the meaningful intercalary of the meaningful structures in this syntaxtic level we can take as an example the normal speech and later see this complex phenomenonin the poetical speech of D.Mehmet. For instance: Good boy,in this syntagma the head that is a noun (boy)leads the subordinate clause the adjective(good),their adaptive connection and the determinant relation remains an endless pontential or...or as: Good/bad/hard working/lazy/handsome/ugly/strong/week boy etc. This potential comes from the paragmatic relation among clauses which serves as derterminant in this relation but on the other hand they are conditioned from the semantic correlation. This structure is not only a potence of the paradigmatic relations or....or,but also a potence of of the syntagmatic

\footnotetext{
${ }^{3}$ According to Chomsky the term meaning in syntax should be substituted with the term"the structural meaning"where the last one includes the lexical and grammatical meaning which in the traditional grammar it is called "the grammatical meaning" where it is discussed only for the meaning that is transformed by the grammatical morpheme forms but without touching the meanings of the units and what is more the meaningful movements(lexical) that can happen inside the units.

${ }^{4}$ The presence of the meanings of a word as a intercalary possibility in the meaningful structure of another word,seen in the psicolinguistic view.

5 The treatment in the theoric aspect(the kinds of syntagmas and the relationship among connection) have nothing to do with the studying material.The superficial study is done becaouse of the clarity of the following treatments over the minimal constructive structures which will be analized in the aspect of the lexical meaningful movements and not only.
} 
relations of the kind and....and,as: golden boy (meaning great boy).In this syntagma the relationship among words is the actual position of different meanings in the hierarchy of the word structure as in the word gold. The word gold in the syntagma golden boy according to the "Albanian Dictionary of 1980 carries meaningful notions of the fourth meaning: This is translated as A dear, good, and lovable person(usually for children).Mother's golden child (precious). (Albanian Dictionary, 1980; 489). However, according to the "Albanian Dictionary" of 2006, the word gold has two figurative meanings which have a great tendency of abstaction but here it is noticed a narrowness of the meaningful hierarchic structure. In 1980 the word gold comes with 7 meanings, wheras in 2006 it comes with four meanings. In the" Albanian Dictionary" of 1980 the figurative meanings of this word come in two schemes where the level of abstraction in the fourth meaning is higher and in the sixth one the level of abstaction lower.

Figurative with a high level of abstraction in which is is reflected the close semantic relationship between this word and the word $b o y^{6}$ and we have the gold as a noun.1 a yellow precious metal.2.coins or other articles made of gold which are used as jewelry the gold around her neck 3.fig.translated as a pecious person(usually for children).4.as an adj.,fig.golden means darling,precious, beautiful,dear marvellous;golden coins ;golden boy.gold in the mud which is translated a light under the bushel,precious but in a place where it can not be seen or where it is of no use. (The Albanian Dictionary",2006; 236).

Well,here we can see a narrowness of the semantic structure in the word gold increasing the level of abstraction which leads to the other new figurative meanings with a different semantic notion. This is conditioned by the first "metaphoric" connection.

The metaphoric relation is very important to explain the meaningful movements in all levels of speech,for this reason it is considered to be an effort of motivation in naturalizing language.

"In an effort to to experience the natural derivation of language,Greeks raised a set of principles which explained the width of the meaningful circle of a word over its real one or its source.The most important principle is the metaphor, which depends on the natural connection between the first and the second referent where the word is used.In each case it has been noticed a formal or functional similarity between referents." (J.Lynos,(1968)2001:376)

Metaphor is showed as the prime principle of the meaningful movement. This is noticed in all kinds of metaphors. The absolute metaphor springs from a a prime situation,original,which calls for experience in order to remember the compasision of a view in a short period of time(the presence of a meaning in a short period of time,or of a meaningful relationship unforgettable for its own nature)A concrete situation in which the metaphor is present starts and disappears gradually in the importance of the metaphoric connection although the first nouns faint in the adjective quality.

"The absolute metaphor can exist in one of the right images,often facing other images to create(use) words which create the meaningful move from reality into carring another meaning but in a large space of time.Metaphor cames as an expression stonger than the imitation. It exists a full potency in the autonomy of the figure of speech(metaphor)from its appearance,the partly radiation of the meaning to the person who gets it(the receiver)" (R.S.Furness, Expressionism, Routledge,1973). In Albanian language such metaphor is he is born a poet a sematic-syntactic structure which comes from the semantic-syntactic to be born,with the passing of time the structure born a poet has lost its way from the first structure where it originates so that is showed as an absolute semantic -syntactic structure which carries other meanings already not sementically investigated from the first moment when it came out becaouse the characteristics of the process are disappeared in the metaphoric connections of the words. The metaphoric relations among words in the minimal structures have very often served to complete the lexical gaps in the absence of a prime word in order to name a part of reality. This can be seen in the catacresis metaphors like the food of the mountain,the legs of the chair, The head of the needle or the eye of the needle is based on the similarity among phenomenons. This is obvious although many metaphors are a natural extention of metaphoric images compared to their first formal appearance.(Geraldine E.Van Rijnvan,Metaphor in Medical Texts,Rodopi,1997)

The words in the katakresis metaphors are used in a sense of accomplishment,in an order to complete the blank in the dictionary(J.David Sapir."The anatomy of metaphor"in "The Social Use of Metaphor,edited by J.David Sapir. and J.C Crocker,University of Pennsylvania Press,1997).

It is very important to be pointed out that the metaphoric denominations can not be so without the minimal syntactic structure(syntagma) which makes it possible to create a structural denomination in order to express opinions,ideas, concepts, sharing experiences etc.

\footnotetext{
${ }^{6}$ The detailed treatments of semantic structures in the syntagma structure of the normal speech has been done to show the power of connections among words in the minimal stuctures but not to be excluded from the syntagmatic structures of the normal speech as the syntactic stuctures of the poetical speech are part of the object of this research.
} 
On the same transferation of meaning,are shown the semantic meaningful movements which are;metaphoric transferation,the metonymical transferation;the break or the addition of the semantic axis.From this point we see the main meaningful axis like simple-derived,concrete-abstract,direct-figurative"(Jani Thomai,2009;142.)

Building such structures at first has been sematically not acceptale but by the passing of time these structures have become part of the speaker's consciousness in the proper language because the relationship among parts included have lost the connections with the first structure.In the structures of metaphors, deep structures completed at the beginning become natural by by being blended with the superficial structures of the semantic presentation during years.

What happens with the poetical speech when we know that the relationship among words is not a normal semantic relation?

In the poetical speech the relations among the acceptable structures(normative)and the new semantic-syntactic structures remains completed only in the first presentation like the structure of metaphor itself.

In these structures the connection among words does not remain in the level of the static correlation but it creates opportunities to carry meaningful movements creating new meanings. Their connections are somehow less natural in the connections of the syntactic structure in poetical speech,always actualizing the deep syntactic structures.

"The deep structures come as a result of the organization of the poetical speech and of the poetical strategy in the conceptional and written plan which can be focused on the literary theory and practice"(Ibrahim Rugova,2007;117)

In the poetical speech the words enter in a semantic-formal and special syntactic relationship with each other. However,this is not the normal order. The break of this normal order of connections starts from the genesis of the syntagma,naturally on stylistic purposes.

The break of this order(the normative rules of speech)is not only of the formal nature but of the semantic too where a special place plays the concept and the culture.

This makes us search for what is called the complex metaphoric structure,based on the linguistic ${ }^{7}$ experience of the past between the sender and the receiver(the author and the reader).

This discursive situation indicates that the complex metaphor is based on simplicity(modesty), which is the return on connections that exist on bases of experience.(Zoltan Kovences; 2005). D.Mehmeti's poetry is the source of "monstrous"semantic,formal and syntactic relationships.In this poetry,the taboos are broken expansion of the semic structure of the second meaning with a clear tendency toward a new meanining and we get:feeling,the phenomenon stable(pain),created throughout years not only because of a loss, a pain turned into rocks, walls, the whole long-suffering where on the top of which exists dolour.

Moulded air ${ }^{30}$ (Din Mehmet(1974),2009;192).A syntagma with adoption and a determinant relationship.In the syntactic aspect it is regarded as a syntagma with a mutilated power of semantic relations and with a potence in the absence of relationships or...or paradigmatic. The conditioning of this superficial structure comes from the semantic order of the deep structural structure.The conditioning of these relationships comes as a result of the semantic nature of the second lexema. The meaningful and figurative structure of the adj.moulded is built from the sems such as:the backwardness compared to time, the sloth,the backwardness in thoughts,viewpoints etc. However,the lexema air in this structure comes with a figurative meaning:3.fig. Environment; climate. Change air,the air of freedom ${ }^{31}$.

In the above syntagmatic structure the adjective moulded is presented almost independent from its meaningful and figurative meaning,but it carries semantic features of the root from which it derives by negleting the theme(the past participle of the word mould;mould-ed) from which it derives in a direct way.In the actualization of these sems,already of the word the-mould it is displayed the meaning of each risk that the lexema mould carries. The semantic relationship among the parts of syntagma moulded air creates an actualization of potential sems of the word moulded in a strange report relating to the nature of the semantic multitude among the roots of the words created from them.

This semantic relationship in this level of discursive structure makes it possible to enrich the the figurative and meaningful structure of the lexema moulded and we get:the backwardness compared to time ; the sloth ; the backwardness in thoughts and viewpoints, the presence of an overall risk.

This extention of the meaningful and figurative structure creates the possibility for a new meaning,which remains in the level of a bridged meaning in order to reach the level of a new one.Here we get:Something which is considered to be a health hazard in the environment where it lives,and in no way can it be negleted as it circulates in the endless space,an inevitable risk.

The walled lights ${ }^{32}$ (Din Mehmet(1974)2009;192).A syntagma where its parts are connected by being adopted to

\footnotetext{
${ }^{7}$ Every language is characterized from its semantic unicality, based on the relations of experience at speakers of that language,so the figurative semantic relations are based on the relations of of the psycho-social experience at speakers of a revelant language
} 
each other.

We can say that in this syntagma we have a calcination of the syntagmatic relations, with other words, a presence in absence, a presence of the adjective and only in the absence of the possibilities to substitute it with a lexema of the same seed.In the paradigmatic relationships too such as or...or they are impossible because of the semantic relations. The walled lights are such and they can not be different,but on the other hand they can not have other qualities but only walled ones.

The syntagma of the walled lights is presented with an abritary conditioning of the length,what Chomsky calls it as the a syntagma with an abritary length ${ }^{33}$ (Noam Chomsky,(1957),20011;36).

In the fulfillment of this syntagma,semantically for the first lexema we have the actualization of the figurative sems of the figurative meanings but not of the same meaning as a whole.So,in this requisition we have light as a complex of rays which shine and glare on bodies and it is recieved by the human eye, a space or lightened place,the viewpoint,a way of looking or presented according to the clues,something that broadens the mind etc. The lexema walled is presented with the second meaning,in which with a great interest is presented the sem closed somewhere alive into walls and left to die there (as a punishment). ${ }^{34}$

With the same semantic structure is also presented the word walled in the dictionary of 2006. The semantic relationship among the parts of the syntagma as well as the poetical contex in which this syntagma is presented(It is set on fire/Have no time to weep;The walled lights /something/Have no time ${ }^{35}$ (Din Mehmet(1974),2009;220),make possible the realization of the most abstract sems from which new sems are produced toward a new meaning. The presence of light as brighteness,as knowledge,as viewpoint and as vision it raises individ's conciousness(captiveted people) for freedom;its wall creates unsuitable conditions for the individ's and peoples' captivity and domination ,the element of time that is identically linked to the semantic of this syntagma is in fuction of the absence of the daylight.

In this case the lexema light comes out with the semena of freedom<light/vision,the raise of conciousness for freedom) despite being walled.The second element of syntagma carries the semantic of the traditional sacrifice for existence,although it is walled it would continue to lighten the soul of the people who desire freedom for Kosovo during hard times of invasion.

The spit of automn ${ }^{36}$ (Din Mehmet(1974),2009,241)A syntagma with direction and with a determinant relationship.A syntagma when the syntagmatic relations(and...and) and paradigmatic ones (or...or) are in a possible potential.

The semantic relationships among parts are relationships created on bases of similarity among phenomenons(spit(n/v. rain) with a semantic direction from the head spit,already with a shift in meaning not as a proces but as a phenomenon and all this in an anology with the phenomenon/process rain(there is not a special form in Albanian to name the process of the rainpour as:rain-ing so this process is used in this way rain-ing wich in many cases is presented as elliptical in the form of rain>it is raining).

The syntagma the spit automn is build in analogy with the structure the automn rain.Semantically this syntagma is a bit strange because the amount of of spit that is produced is very small,while we know that in automn rainy days are frequent.In order to avoid the meaningful disarragement among parts of the superficial syntagma,but of the deep structure,the research on the meaningful difference should be searched in the qualities that the spit carries;then it should be done an analogy with rain as a natural phenomenon in a certain season(automn).In the linguistic aspect this syntagma breaks the taboo of the semantic harmony among parts in the deep syntactic structures which condition the formal harmony of the superficial syntactic structures.In the aspect of the superficial syntagma, it is presented as formally standatarised,while semantically it remains decorated through the analogy and the metaphoric relations. These kinds of syntagma can be found in the corps of the following syntagmas in which the meaningful movement in the semantic structures of its elements it is presented obviously with a tendency of the semantic enrichment by moving into higher levels of abstraction.

To have a sharp eye,embrance a situation, deadly fear,the roads of life, the water swarms with life,to shed tears of joy, the autumn of life, the heart of the sea, a word in season,bark at the wrong tree,to kick the beam,the lonely hearts, a lone wolf,the words blew away,to be swollen with emotions, to be green with envy,to have a ball in the throat,hills of beans, To cherish a snake in my bosom, angel's masks, a knife mask, the soaking wet air of autumn.

What happens with the word in the heart of the sentence?The meaningful movements are not only realised within the structure of syntagma or the structure of the sentence?Certainly,the meaningful movements among words do not end up in the in the structure of syntagma ,they continue to become more diverse in the structure of the sentence. The presence of many different lexical-syntactic elements makes it possible to fulfill the semantic contours of a meaningful movement from a lower scale of abstraction to a higher one. This is the reason of regarding the sentence as a minimal unit of communication,grammatically orderd,which expresses the content in the perspective of its own connection to 
reality(according to J.Ries).

There are cases when we have disorganisation in the nature of the formal grammar,this depends on the level of the sentence ${ }^{8}$.

Hot-tempered he switched off the light/That dream Din Mehmet(1974),2009;200).

The syntactic structure of the word is realized on bases of inversion,but it avoids the normal grammatical order among the parts of the sentence.In order to have a better idea of the poetical syntactic form and thegrammatical inconsistency let us form the normal order without changing the grammatical categories among pats included in verses. That dream/Bad-tempered he switched off the light.The inversed construction puts before the quality of the dream,its state before completing an action.Well, a dream angry for a long time,bad-dempered it switches the light of the long journey,it avoids the guide toward the roads of life and it is found in the crossroad of darkness. The metaphoric movement is realised by being based on the meaning it carries in the actions of people toward a mystical phenomenon of the human nature.In the abstract ${ }^{9}$ plan of lexeme dream we have:to do away a deep desire,but an angry one. Exactly ,this desire comes as a result of abandoning the lightened streets from the guided lights. This movement is made by being based on the scheme :dream>a wish to do something that we want to be fulfilled in the future;light>guide,the way we should follow to realise our desires.

The grammatical incompability between the defining and the defined ${ }^{10}$ word,maybe is a linguistic experiment to define the gender of nouns which do not have a natural motivation of gender.However,the compability of gender in certain cases displays the power of the noun .A manly anger is greater than that of a female. To support this thought we can bring the inversion, when the logical stress is directed on the adjective angered and not on the noun dream.

Angered, he switched on the light/That wakefulness ${ }^{41}$ (Din Mehmet(1974),2009;200).

We have a repetition of the above poetical structure.A syntactic inversion order but in an antitectic position with the previous verses.We have also an incompability between the formal grammatical compability of the defined and the defining word.To make things clearer about the form of the poetical syntactic and about the grammatical incompability,let's form the normal order without changing the grammatical categories in the components of the verses. That wakefulness/Angered he switched on the light. The inverse construction puts on the foreground the quality of wakefulness, its situation in the moment of completing the action. The wakefulness angered for a long time,high-tempered he switches on the light towards his journey,searches his guide in the ways of his life, he tries to pass the cross-road of darkness. The metaphoric move is realised by being based on the meaningful transfer of people's activities toward a real phenomenon of life.In the metaphoric mov, a light is being searched in the real life of the lyrical self -interest ,a power that turns on the light toward the life journey and neglets dreams. The anger of a male is stronger than the anger of a female.By sustaining this idea,we can bring the inversion too,when the logical stress is directed to the adjective angered and not to the noun wakefulness.

The semantic incompability is not the same for the poetical expressions but for the collective linguistic consciousness it is. This incompability is a possibility of actualizing new meanings as well as creating new ones etc.

\section{Conclusions:}

1. The word comes in a potical fulness regarding three aspects as in the conventional side in connection with the other words and in the raport with the user.

2. The smallest units of the saying,syntagmas, are essential in the fulness of the word meaning.The syntagmas sign the lower unit of a saying from where it starts the analysis of the whole meaning of the saying.The last one is made of the structural and lexical meaning.

3. The creation of the minimal units is based on the deep and superficial structure,where the last one has a double conditioning,the formal and the meaningful (lexical).Deep structures are conditioned deeply in the semantic aspect but built according to the grammatical principle(the entire rules) totally independent from the

\footnotetext{
${ }^{8}$ Our analysis consists of the semantic relations in the syntagmatic level but in this part of work we shall try to make a semantic-formal analysis,because the poetical form displays meaningful and grammatical potencial,but not ony this. This analysis in a level of the sentence testifies the close formal relations(as a way of expressing grammatical meanings)and sematic(lexical)

${ }^{9}$ The explonation of the metaphoric move is a necessary to understand the experimentation of the inconsistency among the parts of the verse

10 In the cases when the motivation of the grammatical gender is not motivated from the natural gender,we refer to the formal identifiers of the certain noun and to the determinants which determine, but in our case we do not have such compability between the noun and the relevant adjective
} 
semantic effect(lexical).

4. The syntagma is the minimal unit of a structure where the first meaningful movements happen such as:the actualization of the most abstract meanings, the creation of the bridged movements,the figurative meanings and in the end the creation of new meanings in the hierarchic structures of the word.

5. The syntagmas in the poetical speech break the taboo of the semantic and grammatical relation of the normal speech. The units of its structure enter the relations and connections somehow completed compared to the normal speech.The deep structures are present a bit more in the poetical speech, where the superficial structures are showed insignificat, in the formal aspect too.

6. The syntagmas of the poetical speech are a potential of the semantic development of the words in a language as in the semantic narrowness and in the semantic width too. The poem of Din Mehmeti is a full evidence of the semantic phenomenon in the minimal structures of the poetical speech.

7. It can be claimed that the first metaphoric relations of the words can be founded in the structure of the syntagma as an effort to explain the linguistic naturalization and not only this.

\section{Bibliogaphy}

The Academy of Science of the Albanian Republic, The Albanian Dictionary,Tirane,1980.

The Academy of Science of the Albanian Republic, The Albanian Dictionary,Tirane,2006.

Din Mehmeti, (2009) The literary work nr 1,"Ora"(Pristina, 1974) Pristina.

Ibrahim Rugova (2007), "Kritika"The Academy of Science nand Arts of Kosovo, Pristina.

Jani Thomai, (2009), "The meaningful background in Albanian language"( Semantic lexical), EDFA, Tirane.

John M. Lipski, "Poetic deviance and generative grammar", A Journal for Descriptive and Theory of Literature 2(1977),241-256, pg.242

John Lynos,(2001) "An introduction in the theory of linguistic"Dituria, Tirane.

Giorgio Graffi,(2003), The syntax, The structures of speech,Dituria,Tirane.

Noam Chomsky, (2011), "Syntactic Structures", Tirane,Dituria.

Rexhep Qosja"The cult of the song",at Din Mehmeti, The literary work nr.5, Drenusha,Pristina,2009.

Rami Memushaj(2003),Tirane, "Hyrje ne gjuhesi" (An introduction into linguistic),Dituria.

M.Gareth Gaskell, (2007) "The Oxford handbook of psycolinguistics ", Oxford University Press, New York. 